\section{Editorial Advisory Board}

Mila A. Aroskar, R.N., Ed.D.

Associate Professor

School of Public Health

University of Minnesota

Jane A. (Raible) Boyajian, D.Min.

Director

Center for the Shaping of Values

United Theological Seminary of the Twin Cities

Ann W. Burgess, D.N.Sc., F.A.A.N, Director of Nursing Rescarch

Dean ad interim

Boston University School of Nursing

Lori Costa, R.N., M.A., J.D.

Manager for Grants and Contracts

San Francisco Dept. of Public Health

San Francisco. California

Helen Creighton, R.N., J.D.

Distinguished Professor of Nursing

School of Nursing

University of Wisconsin at Milwaukee

Anne J. Davis, R.N., Ph.D., F.A.A.N.

Professor

School of Nursing

University of California, San

Francisco

Sally Gadow, R.N., Ph.D.

Assistant Professor of Philosophy

College of Medicine

University of Florida at Gainesville

Leonard H. Glantz, J.D.

Assistant Professor of Law \& Medicine

Boston University Schools of Medicine and Public Health

Nathan Hershey, J.D.

Professor of Health Law

Graduate School of Public Health

University of Pittsburgh

Barbara F. Katz, J.D.

Associate Counsel

University of Massachusetts

Ingeborg G. Mauksch, Ph.D., F.A.A.N. Professor of Nursing

Vanderbilt University

Nashville. Tennessee

Frances H. Mfiller, J.D.

Associate Professor

Bosion University School of Law

Catherine P. Murphy, R.N.. Ed.D.

Assistant Professor of Nursing

Boston University School of Nursing

Lisa Newton. Ph.D.

Professor of Philosophy

Fairfield University

Fairfield, Connecticut

Elliot L. Sagall, M.D.

President

American Society of Law \& Medicine

Boston. Massachusetts

Judith P. Swazey, Ph.D.

Executive Director

Medicine in the Public Interest, Inc.

Boston, Massachusetts

\section{Announcement}

The editors are pleased to announce the appointment of Elizabeth M. Ollen as Assistant Editor of Nursing La11' and Ethics. Ms. Ollen holds a Muster's Degree in English from the University of Massachusetts at Boston. She has previously edited several books and articles in the health law field.

\section{New Philosophy (Continued)}

An individual may sustain an "unhealthy" drug dependence in order to have available all of her energy for dealing with an overwhelming grief. She chooses to care for the part of the self that is suffering and in effect may be using the drug as a responsibte form of self care. The objection will arise that this is not true self care, but is, at best, misguided; at worst, irresponsible or abusive. But a nursing philosophy cannot have it both ways. Either a decision is valid because it is based upon selfdetermination and represents the individual's own definition of self and self care, even if that definition conflicts with objectively established standards. or objective norms are imposed as the. appropriate standard of care. In that case, nursing care is not based upon a philosophy of self care, but upon the tradition of prescribed care.

A second difficulty with objective definitions of self and self care is that the self is unique as well as complex. The fundamental needs that health care addresses may be universal, but they are perceived and understood in different ways by individuals. Therefore, no universal standard of care is applicable. Any generalization compromises uniqueness. since it assumes that individuals are more alike than different. This assumption has merit, of course. if we are concerned with imposing general norms upon patients. But the adoption of health behaviors by an individual in compliance with standards governing people in general does not constitute self care. The basis of self care is self-determination, freely exercised choice expressing the unique understanding and values of the patient rather than the normative expectations of health authorities. Paternalism, the coercing or forcing of persons to act in their externally defined best interest is - to repeat an earlier point - not only morally but logically impossible in this view. Because each self is unique, a valid decision about the best interest of an individual cannot be made by anyone except that individual.

The uniqueness of the self is especially significant in relation to persons who, we readily admit, differ from the "normal," but who - for that very. reason - are allowed less selfdetermination than other persons. I alluded to this issue when I observed above that many professionals feel that a need for assistance in making one's health care decisions is tantamount to the need for professional decision mak. ing. According to that belief, the greater the health need, as in severe injury or life threatening illness, the greater the justification for substituting professional judgment for patient selfdetermination. In extreme situations, of course. patient decision making often is not feasible because of uncontrolled pain, disorientation, or other reasons. But in nnn-acute situations the reasons for an "objective" best interests judgment are not as clear, for example, as in the case of chronic phys. ical, psychological, or intellectual handicap, early childhood, advanced age, and so on. Persons in all of these situations deviate so far from " normal" health needs that we have even developed clinical specialities to address their needs. Yet, for persons in these very groups, we seem to know lesss rather than more about their distinctive self care needs, in particular. their need for assistance with self care agency. It is not an exaggeration to say that the more unmistakably unique a situation is, such as the self care of a multiply handicapped person, the more likely we are to tailor our assistance to general standards rather than to decisions arising out of the uniqueness of the individual.

\section{The Role of the Nurse}

How does the nurse assist patients in the exercise of self-determination? That assistance involves actively helping individuals become clear about what they want to do, by helping them t clarify their values and beliefs and, on the basis of that clarification. to reach decisions that express their understanding of themselves and their situation.

That assistance is needed because clarification can be the most difficult when it is most needed: when a situation arises that calls into question beliefs and values so deeply embedded in a person's life that they are the least defined or developed.

(Continued on page 6) 